\title{
O PODER JUDICIÁRIO DIANTE DO \\ NOVO CICLO DE GREVES NO BRASIL
}

THE JUDICIAL BRANCH AGAINST THE BRAZILIAN

NEWEST STRIKES CYCLE

RESUMO: O presente artigo analisa criticamente o padrão de resposta judicial às novas tendências grevistas no Brasil, em particular às greves por fora do sindicato. Para tanto, parte-se do conceito empírico de ciclo de greves, a fim de captar uma imagem aproximada do cenário sindical no momento presente. Num aspecto geral, defende-se o surgimento de um novo ciclo de greves em 2004, cujos sinais de esgotamento já se fazem presentes. A singularidade deste ciclo, nos anos de maior intensidade (2011-13), reside na aparição de greves em setores com pouco histórico de luta e de greves for fora do sindicato. Pelo elevado número de greves, parece ter havido um "transbordamento" da atividade reivindicativa, fazendo com que paralisações irrompessem sem a presença dos sindicatos. A análise desta jurisprudência demonstra, finalmente, que a Justiça do Trabalho, apesar de proteger individualmente o trabalhador nas situações de "greves selvagens", mantém seu padrão de sofisticado controle repressivo no que tange ao direito coletivo do trabalho, enveredando-se numa tensão constante no âmbito do sujeito de direito.

Palavras-chave: Greve. Ciclos de Greve. Poder Judiciário. Greves por fora.
ABSTRACT: The following paper studies the pattern of judicial response to the newest strikes trends in Brazil, particularly to the wildcatstrikes. Therefore, the starting point is the empirical concept of strikes cycle, able to capture an approximate representation of actual union scenario. Generally, the study defends the emergence of a new strikes cycle in 2004, whose depletion signs are already presents. The singularity of this cycle, at the peaks in 201113 , is the expression of strikes in sectors with lack of struggle history and the strikes busted out of unions. By the high number of strikes, seems to be happened an "overflow" of claimed activity, making some stoppage without the union. The review of this jurisprudence shows, finally, that the Work Judicial Branch, despites protecting individually the worker at "wildcat strikes" situations, keep its sophisticated repressive control pattern at the collective labor law, entering in a constant tension at the subject of law.

Keywords: Strike. Cycles of Strike. Judicial power. Strikes from the outside.

\footnotetext{
${ }^{1}$ Professor dos cursos de pós-graduação em direito do trabalho da Unianchieta. Mestre e doutorando em direito do trabalho pela Faculdade de Direito da Universidade de São Paulo.
} 


\section{INTRODUÇÃO}

Dentre os diversos estudos destinados ao movimento sindical, há quase unanimidade em reconhecer que os dados referentes à atividade grevista figuram como um importante indicador dos "ânimos" e vicissitudes do sindicalismo, motivo pelo qual a mais autorizada bibliografia das ciências sociais reserva cuidadosa atenção a estes dados. Isto sugere que os indicadores de greves constituam a principal via de acesso para a apreciação do movimento sindical no Brasil (BOITO JR.; MARCELINO, 2010, p. 328).

O que, de modo algum, implicaria em desconsiderar outras ferramentas analíticas que efetivamente logram importantes aproximações à realidade sindical, como as taxas de sindicalização (CARDOSO, 2015; RODRIGUES, 2015), as pesquisas de confiança social (IBOPE, 2015; FESPSP, 2014), as análises das políticas das centrais sindicais (GALVÃO, 2009; KREIN et al., 2015; TRÓPIA, et al, 2013) e os resultados das negociações coletivas (DIEESE, 2016), por exemplo.

De modo resumido, o respaldo que a ação grevista possui dentre os estudos destinados a compreender o mundo sindical deriva de condicionantes práticas e sociológicas. Num espectro mais prático, desde o fim da década de 1970, os dados mais sistematizados e gerais de que se dispõe sobre o sindicalismo referem-se às greves, em consequência do trabalho de coleta, registro e interpretação do Sistema de Acompanhamento das Greves do DIEESE². Já do ponto de vista sociológico, difícil seria contrapor a constatação de que, apesar de não ser a única ação importante do movimento sindical, a greve seria a mais contundente, gerando maior repercussão e visibilidade. Mais do que conhecer a realidade sindical, os estudos calcados neste paradigma ofertam inovadoras interpretações teóricas e buscam influenciar os atores que compõem a cena sindical (NORONHA, 2009; PONCE, 2013; LINHARES, 2015).

Neste sentido, é possível que a percepção das potencialidades cognitivas e instrumentais dos indicadores de greve tenha conduzido Eduardo Noronha (1992) a inaugurar, no seio da sociologia brasileira, a noção de ciclo de greves. A rigor, trata-se da

\footnotetext{
${ }^{2}$ Departamento Intersindical de Estatística e Estudos Socioeconômicos.
} 
adoção de um conceito empírico deduzido da experiência sindical internacional (PIZZORNO, 1973; TILLY, 1978), uma vez que a história do sindicalismo demonstra que, em diversos países, as greves se comportam de modo cíclico, com perfis característicos, variantes internas e específicas fases de expansão, auge e declínio (NORONHA, 2009). Ou seja, em compreendendo as especificidades e generalidades do comportamento grevista em um período mais ou menos longo, seria possível esboçar um retrato mais aproximado do sindicalismo em cada momento - precisamente o que tal referencial dos ciclos de greves objetiva.

Para o presente estudo, interessa captar as principais determinações do que aqui se assume se tratar do mais recente ciclo grevista brasileiro, despontado a partir de meados dos anos 2000. Elaborado este quadro descritivo, retendo algumas singularidades das dinâmicas grevistas observáveis, será preciso conferir particular atenção a uma característica particular deste novo ciclo: as greves deflagradas por fora ou à margem dos sindicatos, é dizer, sem a participação efetiva destes.

Irrompendo com relativa espontaneidade, apresentando-se algumas vezes com ares de rebeldia e destruição, a realidade sindical presenciou, principalmente a partir de 2011, alguns episódios grevistas às margens das entidades e lideranças sindicais eleitas para a representação legal das respectivas categorias. Seguindo a linguagem corrente, tais fenômenos são denominados greves por fora, que abarcam tanto paralisações deflagradas - com relativa espontaneidade - pelos grupos de trabalhadores no local de trabalho quanto situações de continuidade das greves convocadas pelos sindicatos, após este encerrar o conflito pelos canais institucionalizados.

Sem dúvida, a greve por fora que mais chamou a atenção dos noticiários foi a greve dos garis do Rio de Janeiro, em 10 de março de 2014. As razões para tamanha projeção nacional e internacional que o episódio logrou estiveram relacionadas ao período da greve: o famoso carnaval carioca, quando milhares de turistas visitaram a cidade e ali encontraram uma pilha de lixo acumulado.

Apesar de convocada pelo sindicato obreiro, o Sindicato dos Empregados das Empresas de Asseio e Conservação do Município do Rio de Janeiro, a greve fora conduzida espontaneamente, sem a presença (e contra a posição) das direções sindicais, que já 
haviam capitulado diante da pronta decisão judicial que declarara a ilegalidade do movimento $^{3}$. O desfecho daquele processo foi amplamente noticiado: após oito dias de greve, os garis obtiveram um espetacular aumento salarial de $37 \%$, além de outros benefícios econômicos e sociais e a garantia de nenhuma demissão aos grevistas (GARCIA, 2014). Greves de garis logo foram deflagradas em outras cidades, como Fortaleza, Niterói, Belo Horizonte e São Paulo, estimuladas pela vitória econômica e política dos garis cariocas.

Desde então, diversas outras greves por fora foram deflagradas, notadamente nos setores de transporte coletivo urbano e da construção civil. Neste último setor, entraram na agenda nacional as greves por fora ocorridas nos canteiros das obras do PAC (Programa de Aceleração do Crescimento), possivelmente em razão dos níveis de rebeldia e destruição que se seguiram. Deste conjunto de novas mobilizações grevistas, parte-se uma primeira indagação: estas greves por fora figuram como uma exceção desprezível ou são recorrências dignas de estudo? Para responder esta questão, foi realizada uma pesquisa de jurisprudência a fim de captar a recorrência deste tipo de paralisação.

A partir de então se tornará possível desenvolver o objeto do presente estudo, qual seja a relação entre o fato e o direito; de modo mais explícito, a posição do Poder Judiciário diante deste novo ciclo de greves, o que poderá ser desvelado a partir da análise crítica de jurisprudência nos casos de greves por fora. Neste momento, será importante identificar criticamente os padrões de resposta judicial a estas novas formas grevistas e explorar suas tensões internas.

Como se observa, trata-se de um estudo exploratório que se desenvolve indutivamente à base da pesquisa bibliográfica e de jurisprudência, além da utilização de dados estatísticos de forma dedutiva.

Finalmente, se a caracterização do momento estiver correta (ou mesmo aproximada), sendo adequadamente assentada a atuação do Poder Judiciário, então será possível atualizar a análise crítica deste Poder da República diante da experiência grevista,

\footnotetext{
${ }^{3}$ BRASIL. TRT-1. SDC. Proc. no 0010201-14.2014.5.01.0000. Rel. Flavio Ernesto Rodrigues Silva. Ac. ID no 5dc4839. Publ. 05.08.2014. Acesso em 20 jan.2017.
} 
acompanhando determinada linha de crítica (CORREGLIANO, 2014; BABOIN, 2013; BARISON, 2016).

\section{OS CICLOS DE GREVES NA HISTÓRIA BRASILEIRA}

Acreditando, pois, ser válido, manejável e confiável o conceito de ciclo de greves para exprimir uma dada realidade, seria possível verificar como, na recente história brasileira, tais ciclos ajudaram e ainda ajudam na compreensão do sindicalismo e da própria conjuntura política.

Noronha (2009) divisa um primeiro grande ciclo de greves no Brasil, entre 1978 e 1997, cujos fatores explicativos e causais poderiam ser, primordialmente, localizados nas determinantes da política de redemocratização, em especial na superação da política desenvolvimentista, combinada com um ambiente macroeconômico excepcionalmente instável. E, tal como na maioria dos países, as greves brasileiras nestes vinte anos apresentaram um comportamento não aleatório e cíclico de médio ou longo prazo. É bem verdade que exceções à regra da não aleatoriedade foram visualizadas em alguns momentos, porém relacionadas às "oscilações abruptas segundo as conjunturas políticas e econômicas de um ou de poucos anos" (NORONHA, 2009, p. 120-121). Assim, assume implicitamente o autor que os eventos singulares devem ser medidos pela régua das tendências, em um lapso temporal mais alargado.

Por ora, interessa captar as determinações essenciais deste primeiro grande ciclo de greves, além dos fatores que explicam as suas variações internas. Este modo de olhar a realidade sindical poderia fornecer um caminho para a compreensão do sindicalismo atual, privilegiando as explicações de natureza política em face das determinações puramente econômicas, como os salários, os índices de desemprego e a inflação (NORONHA, 1992, p. 134; PONCE, 2013, p. 31).

Adotando-se, pois, a hipótese deste primeiro grande ciclo de greves que perpassou a crise do regime militar até o fim do primeiro governo $\mathrm{FHC}$, é possível perceber que não se tratou de um ciclo completamente homogêneo, senão fracionado em três fases: a) uma fase de expansão, de 1978 a 1984; b) uma fase de auge e “explosão" das greves, de 1985 a 1992 e; c) uma fase de "resistência e declínio do ciclo", de 1993 a 1997. Nos anos 
seguintes, de 1998 até 2007, apesar das oscilações, as greves teriam atingido um volume ${ }^{4}$ médio e retornaram a um estado de "relativa estabilidade" (NORONHA, 2009, p. 128-141), ao que se concorda apenas parcialmente. Pois, como se verá adiante, principalmente do ponto de vista qualitativo, seria impróprio incluir num mesmo patamar os anos de 19982003 e os anos de 2004-2007.

Assim sendo, aquela primeira fase de expansão seria caracterizada pela retomada da função do sindicato na defesa dos salários e pela utilização da estratégia grevista com vistas àquilo que Noronha denominou "reconquista da cidadania política".

Sem dúvidas, a fase mais intensa deste ciclo foi aquela de 1985 a 1992, não casualmente denominada "auge do grande ciclo". Inúmeros segmentos realizaram suas primeiras paralisações, apesar da vigência, até 1989, da Lei de Greve no 4.330/64. A conjuntura política de transição impediu a aplicação, pelo Governo Sarney, de medidas repressivas contra os sindicalistas, pois os custos políticos da repressão foram ponderados pelo governo. Diversas negociações foram travadas a partir do reconhecimento das lideranças sindicais como legítimos interlocutores. E, como toda fase, este segundo momento não foi uniforme, apresentando um pico de intensidade entre os anos 1989 e 1991, antecedido e seguido por médias anuais mais modestas de atividade grevista, considerando-se a comparação interna a esta fase (NORONHA, 2009, p. 134).

Por fim, a terceira fase de 1993 a 1997 revela o declínio do ciclo, evidenciado pela queda no volume de greves (pouco mais de 2 milhões de jornadas não trabalhadas) e pelas greves de curta duração, situação que perduraria até meados dos anos 2000. É deste período a greve dos petroleiros de 1995 que, segundo Antunes e Silva (2015, p. 518), figurou como o "primeiro combate aberto à política neoliberal de $\mathrm{FHC}^{5 \text { " }} \mathrm{e}$, em nossa opinião, a última tentativa de fôlego do sindicalismo obreiro em se contrapor à política neoliberal (CORREGLIANO, 2014, p. 88-114). Não seria desarrazoado concluir que a derrota da greve dos petroleiros recolocou o movimento sindical na defensiva por mais de dez

\footnotetext{
${ }^{4}$ Volume de greves assim entendido como o total de jornadas não trabalhadas num ano, obtido pela multiplicação do número de grevistas pelo período da greve, mesmo que este período tenha durado algumas horas (p. ex., uma greve de 4 horas é representada por $1 \frac{1}{2}$ jornada, para a contabilização).

${ }^{5}$ Estes autores ainda apontam a profunda significação de inflexão e divisão da CUT neste episódio, pois a central fora incapaz de oferecer uma solidariedade efetiva aos petroleiros em greve.
} 
anos; não sem razão, a imagem da quebra da espinha dorsal do sindicalismo foi generalizada nos discursos posteriores àquela conjuntura.

Em suma, toda a história do "novo sindicalismo" que se conhece provém deste primeiro ciclo grevista. Goste-se ou não, fato inolvidável é que este ciclo preparou a ascensão do primeiro operário à Presidência da República, conformando um processo político decisivo para a gestação do que se acredita ser o próximo ciclo.

\section{UM NOVO CICLO DE GREVES?}

Neste sentido, é possível que tenha despontado, em meados dos anos 2000, um novo ciclo de greves no Brasil (BOITO JR.; MARCELINO, 2010, p. 330). Acompanhando de perto os dados do SAG-DIEESE ${ }^{6}$ que indicam o crescimento do número de greves e de horas paradas, seria possível inferir uma conjuntura de "reaquecimento" dos conflitos coletivos de trabalho.

Com os dados sistematizados até 2008, Boito Jr. e Marcelino (2010) vislumbraram o despontar de um novo ciclo de greves já em 2004, muito em razão dos aumentos proporcionais das greves ofensivas (isto é, daquelas que almejavam novas conquistas) e das greves que obtiveram atendimento total ou parcial (greves bem-sucedidas). Outros dois elementos característicos desta nova fase de retomada da conflitualidade do trabalho seriam a amplitude das greves (greves massivas) e a utilização de métodos que exigem maior nível de organização, como passeatas, piquetes e ocupações.

Greves mais ofensivas, bem-sucedidas, massivas e mais organizadas seriam indícios da chamada recuperação da atividade sindical (GALVÃO, 2014), "tomada como um indicador da vitalidade do sindicalismo como movimento social" (BOITO JR.; MARCELINO, 2010, p. 328).

Apesar de Linhares (2015) preferir demarcar a série grevista 2011-2013 como inauguradora de um novo ciclo, tal delimitação não parece ser correta, pois despreza o processo de escalada grevista acumulada desde 2004 a partir das mudanças qualitativas no

\footnotetext{
${ }^{6}$ Sistema de Acompanhamento das Greves do Departamento Intersindical de Estatística e Estudos Socioeconômicos.
} 
mercado de trabalho. Seria mais razoável supor que os anos 2011-13 seriam o auge deste novo ciclo.

Para acompanhar a discussão, vejam-se as séries históricas do total do número de greves (Gráficos 1 e 2) e de horas paradas (Gráficos 3 e 4), contabilizadas pelo DIEESE (2015):

Gráfico 1: Total de greves de 1984 a 2003

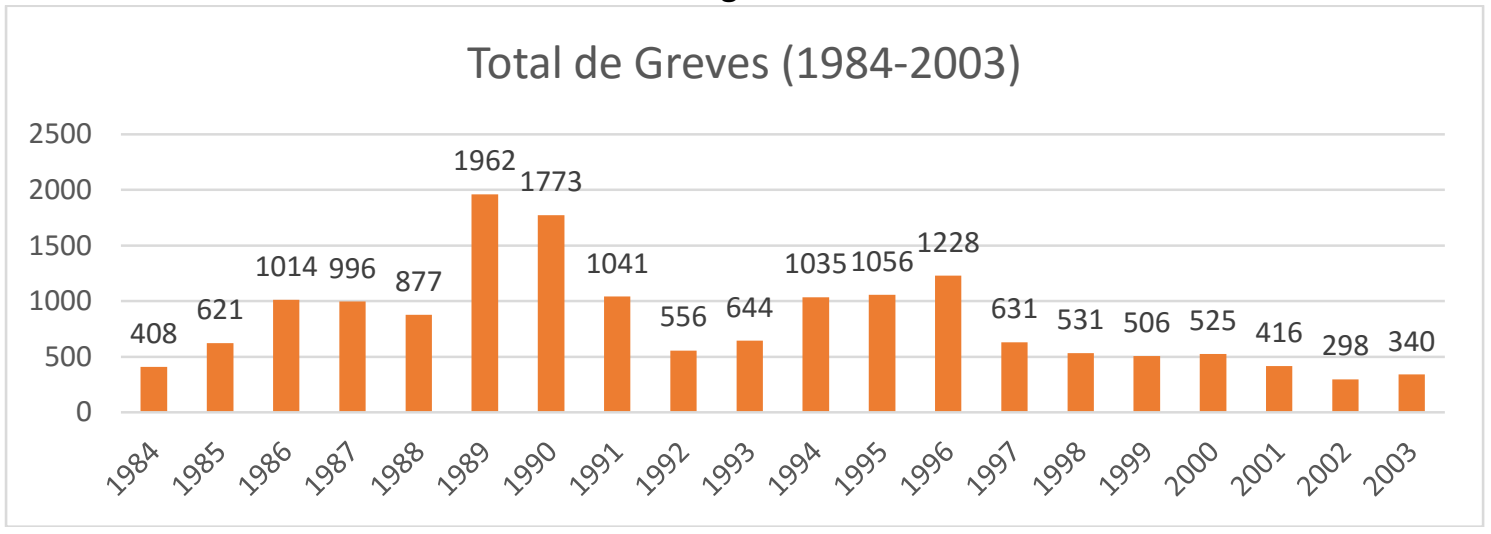

Gráfico 2: Total de greves de 2004 a 2015 (projeção de 2014 e 2015)

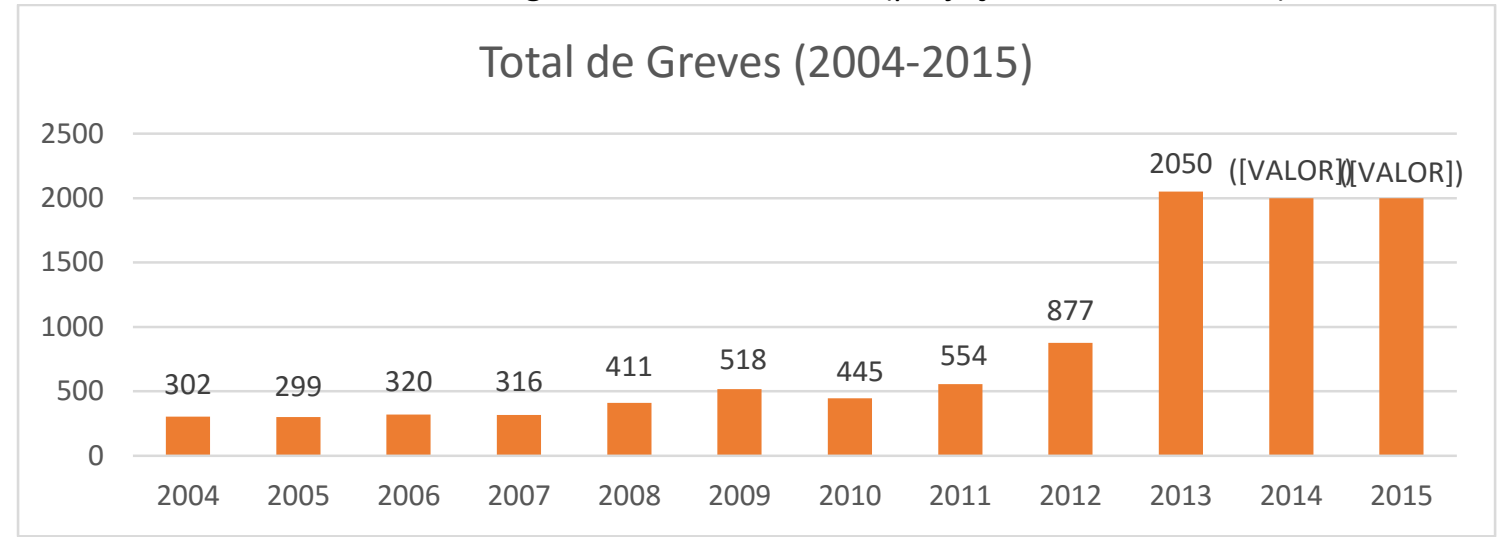

Gráfico 3: Total de horas paradas de 1984 a 2003

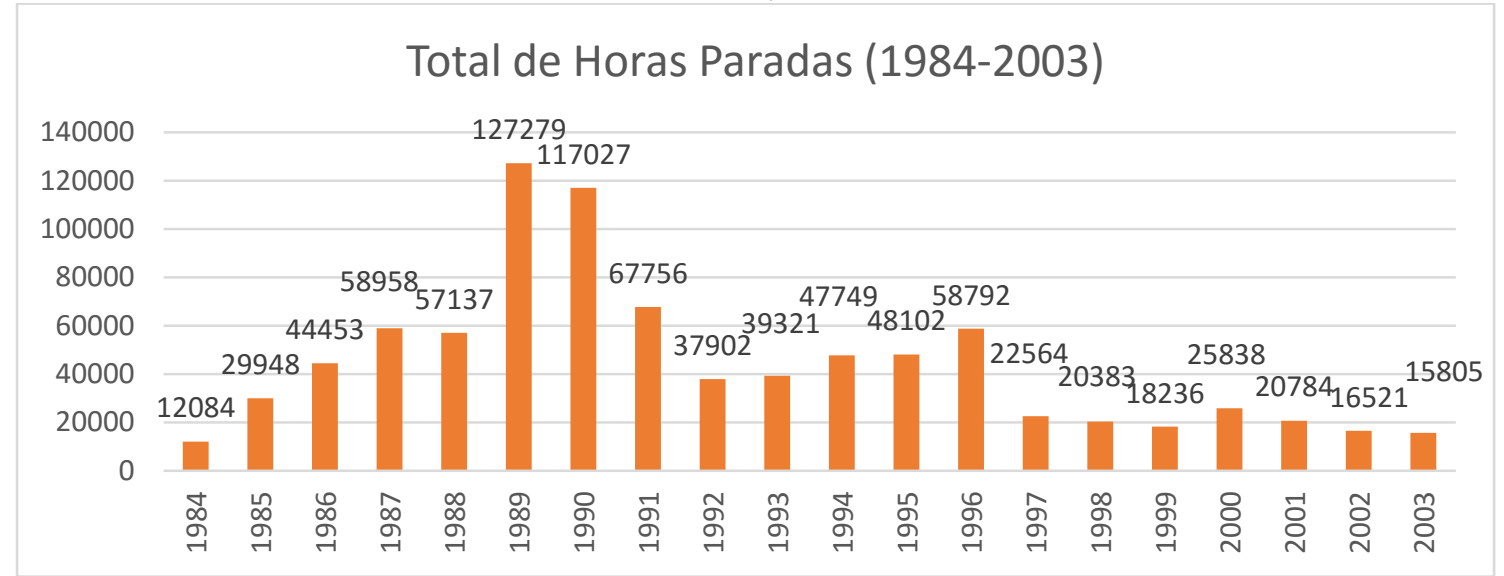


Gráfico 4: Total de horas paradas de 2004 a 2013

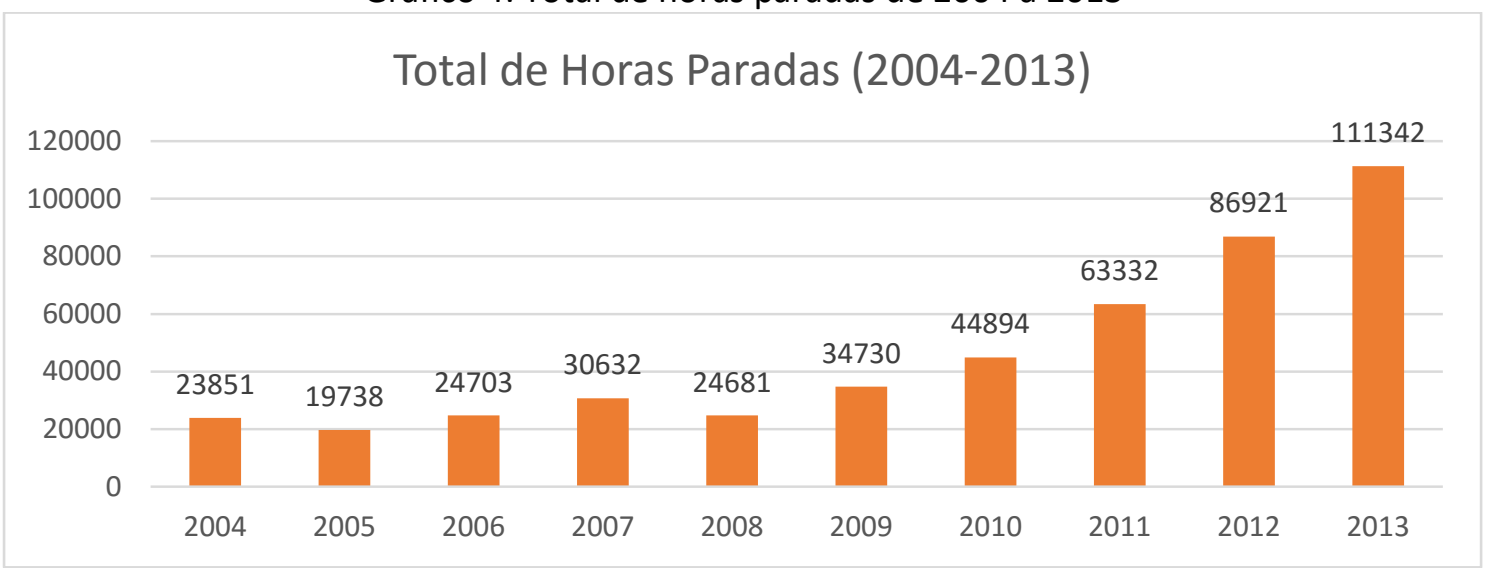

De todo modo, a demarcação do ano de 2011 como marco inicial do ciclo parece não afigurar muito precisa, pois o total contabilizado de 518 greves em 2009 é bem próximo das 554 greves de 2011. De todo modo, por se tratar de fenômeno ainda recente, seria necessário o espaçamento de mais alguns anos para a confirmação mais precisa da datação. O que pouco influenciaria nos resultados obtidos até agora no que tange à explicitação deste cenário sindical revitalizado, revelando apenas distintas ênfases nas variantes econômicas ou mais propriamente políticas para a configuração de um novo ciclo.

Em estudo posterior, com os dados do DIEESE até 2012, Boito Jr., Galvão e Marcelino (2015) reafirmam a hipótese e relembram que um traço característico deste ciclo, até então ${ }^{7}$, teria sido o caráter ofensivo das reivindicações (aumentos reais de salário, conquista ou aumento das participações nos lucros e resultados e planos de cargos), que inverteu a tendência defensiva da década de 90. Além das motivações ofensivas serem um traço peculiar deste ciclo, desde 2004, as greves vinham obtendo melhores resultados para os trabalhadores, como aumentos salariais acima da inflação; se, em 2003, apenas 18,8\% das greves obtiveram reajuste salarial acima da inflação, em 2004 tal cifra atingiu impressionantes 54,9\% (BOITO JR. et al., 2015, p. 158-163).

Amorim busca explicar as principais mudanças da agenda política e econômica promovidas pelo governo federal desde 2003 que induziram a expansão do mercado de trabalho. O que, segundo o autor, habilitaria a elaboração de uma narrativa simples que embasaria o retorno das greves no cenário trabalhista, sintetizada na seguinte sequência

\footnotetext{
${ }^{7}$ Como se verá, tal tendência começou a se alterar em 2013.
} 
“crescimento econômico, redução do desemprego, elevação dos rendimentos, escassez de mão de obra e, finalmente, elevação do poder de barganha dos trabalhadores e seus sindicatos" (AMORIM, 2012, p. 27).

Tende-se a interpretar o termo elevação do poder de barganha como a capacidade subjetiva da classe trabalhadora que, deduzida das condições concretas da economia, levaria à percepção de que seria possível fechar a cada negociação ou greve reajustes mais vantajosos; em outras palavras, o aspecto subjetivo da luta de classes ancorado nas determinantes da estrutura econômica da sociedade.

A esta síntese deve-se agregar outro indicador, importante para a explicação do novo ciclo, qual seja o crescimento dos índices de formalização dos vínculos de trabalho: se, em $2003,39,7 \%$ dos trabalhadores possuíam carteira assinada no setor privado, este percentual foi subindo progressivamente até chegar em 48,7\% em 2011 (IBGE, 2012a) e 49,2\% em 2012 (IBGE, 2012b). Parece razoável supor que o aumento da formalização favoreceu o poder de barganha dos trabalhadores; de modo inverso, sabe-se que a elevação do exército industrial de reserva tende a inibir a classe trabalhadora na reivindicação de direitos e melhorias, ao reduzir a massa salarial, minar a solidariedade e instaurar um ambiente de pouca confiança da classe trabalhadora nas suas próprias forças.

Por derradeiro, a adoção do marco temporal deste novo ciclo se justifica igualmente por outra condicionante política, qual seja a quase coincidência com a época em que o governo federal, face à crise política de 2005, abandonou parcialmente as medidas econômicas mais ortodoxas e buscou se reaproximar do movimento sindical. Quase coincidência porque os efeitos desta guinada nunca poderiam ter sido imediatos. Identificada por Krein et al. (2015) como um segundo momento dos governos petistas, as medidas adotadas conformaram o assim chamado ensaio desenvolvimentista (SINGER, 2015) que dinamizou o mercado interno e melhorou os indicadores do mercado de trabalho. Tal reaproximação, para além da conjunção das principais centrais sindicais em espaços institucionais (como o Fórum Nacional do Trabalho e o Conselho de Desenvolvimento Econômico e Social), consolidou uma frente política (BOITO JR., 2012) 
que uniu contraditoriamente frações da burguesia e as principais centrais sindicais, estas unificadas na Agenda dos Trabalhadores pelo Desenvolvimento ${ }^{8}$.

Bem, se o caminho até aqui traçado buscou justificar a utilização do conceito empírico dos ciclos de greves, delimitar sua abrangência e esboçar um quadro aproximado e atual do sindicalismo brasileiro, o próximo passo será identificar algumas nuances que conferem a singularidade ao ciclo atual, e que possuam relevância no que tange à incidência do aparato judicial.

\section{AS CARACTERÍSTICAS DESTE NOVO CICLO: AS GREVES POR FORA DA ESTRUTURA SINDICAL}

Não parece haver dúvidas de que este novo ciclo de greves iniciado em 2004 apresentou uma subfase "explosiva" de 2011-2013, quando se concentraram o maior volume médio de jornadas não trabalhadas. Apesar de os dados somente terem sido sistematizados até 2013, com suas 2050 greves e 111 mil horas paradas (DIEESE, 2015, p. 43), Linhares (2015, p. 98) sugere que esta média de duas mil greves tenha se mantido em 2014 e 2015.

Mesmo que isto se confirme, o ano de 2013 traz algumas características que parecem impor um novo padrão qualitativo das greves, assim sintetizado: a) a predominância do caráter defensivo das pautas de negociações; b) a frequência das mobilizações em determinadas categorias profissionais, sendo agora em sua maioria da esfera privada e; c) a ênfase no local de trabalho. Vejamos cada uma destas características tendenciais.

Se, em 2012, a maioria das pautas de reivindicação era considerada de caráter ofensivo, almejando-se novas conquistas ou ampliação dos direitos já conquistados, em 2013 preponderaram as reivindicações defensivas ${ }^{9}$. Tal inversão poderia estar relacionada

\footnotetext{
${ }^{8}$ Tal agenda buscou a valorização do salário mínimo, a redução da jornada de trabalho, o fim do fator previdenciário, a criação de mecanismos contra a dispensa imotivada e a regulamentação da negociação no setor público (KREIN et al., 2015, p. 127).

${ }^{9}$ O DIEESE considera propositivas as greves por novas conquistas e defensivas as greves "que se caracterizam pela defesa de condições de trabalho vigentes, pelo respeito a condições mínimas de trabalho, saúde e segurança ou contra o descumprimento de direitos estabelecidos em acordo, convenção coletiva ou legislação" (DIEESE, 2015, p. 8).
} 
com a entrada na cena sindical das categorias mais frágeis em termos de massa salarial, de condições de trabalho, saúde e segurança e de organização sindical, o que denotaria este relativo "atraso" das pautas de reivindicação. Ou seja, o processo combinado de expansão salarial e aumento de poder de barganha dos trabalhadores nos últimos anos alcançou até mesmo as categorias com menor capacidade de pressão, fazendo com que demandas básicas reprimidas, em geral relacionadas às condições laborambientais, deixassem de ser aceitas e adentrassem nas pautas de reivindicações (LINHARES, 2015, p. 111).

Uma segunda característica marcante destes dados de 2013 seria o crescimento abrupto e não homogêneo das greves, não se concentrando apenas nas categorias que historicamente são mais mobilizadas. O que é apontado pelo DIEESE como uma espécie de "desbordamento", utilizando-se de uma metáfora topográfica para inferir que as greves estão partindo do centro (isto é, das categorias usualmente mais dispostas à luta, como os metalúrgicos, os trabalhadores da construção, os bancários e os servidores da saúde e da educação) à periferia, estes ligados à indústria da alimentação, à limpeza urbana e aos serviços de vigilância privada e pública da rede municipal (DIEESE, 2015, p. 40-41). Inclusive, esta segunda característica ajuda a explicar a primeira, afinal estaríamos diante de "novas" categorias que lutam por "velhas" e represadas demandas.

Quanto à abrangência, deve-se reter a importância do local de trabalho. As greves de 2013 seguiram a tendência do presente ciclo, evidenciando a forte conflitualidade referenciada nas empresas ou, no caso dos servidores públicos, nas unidades. Apesar das greves por categoria ainda serem majoritárias no funcionalismo público (75,6\% em 2013 contra 78,7 em 2012), na somatória das esferas privada, empresas estatais e funcionalismo as greves por empresa/unidade representaram 62,9\% em 2013, contra 57,4\% em 2012 (DIEESE, 2015, p. 6). No fundo, este aumento da participação das greves locais no quadro geral reforça, senão confirma, a tendência já apontada por Boito Jr. e Marcelino (2010, p. 335), para quem o estudo do movimento sindical contemporâneo:

pode requerer, mais que em outras épocas, a atenção para o conflito no local de trabalho. A substituição das greves por pequenas paralisações por setor no interior de uma mesma empresa - modalidade de ação que cresceu na Europa, e que cresceu, como já dissemos, inclusive devido às novas formas de organização 
do trabalho na empresa capitalista (Béroud, 2008) - pode, também, estar ganhando corpo no Brasil.

A estas três dinâmicas destacadas pelo DIEESE seria possível introduzir um quarto indicador qualitativo/quantitativo a ser observado, e que aqui interessa sobremaneira, que seria o tempo de duração mais curto das greves de 2013. Em 2012, 30\% das paralisações foram encerradas no mesmo dia em que foram deflagradas, cifra que aumenta para $49 \%$ em 2013. Reforçando este diagnóstico, podem ser extraídos outros dois fatores: a) $28 \%$ das greves deflagradas em 2012 duraram mais de 10 dias, ao passo que apenas 16\% das greves de 2013 foram enquadradas neste critério temporal (DIEESE, 2015, p. 3-4); b) comparando-se estes dois anos, houve uma considerável diminuição do índice de horas paradas por greve, calculado a partir da divisão do número de horas paradas pelo número de greves - de 45,8 horas/greve em 2012 para 30,5 horas/greve em 2013 no setor privado e 167,87 horas/greve em 2012 para 91,9 horas/greve em 2013 no funcionalismo público.

Como síntese, em 2013 foram deflagradas mais greves que tiveram menor tempo de duração, com pautas mais defensivas, privilegiando os locais de trabalho e com categorias com pouco histórico de luta, o que tende a se aprofundar nos anos seguintes em razão do cenário de crise econômica.

Tendência esta que poderia explicar alguns eventos esparsos ocultos no sindicalismo contemporâneo, quais sejam as greves por fora da estrutura sindical. É dizer, foram tantas as greves produzidas que parece ter ocorrido uma espécie de "transbordamento" para fora dos sindicatos. Confirmando a tendência das greves localizadas e de curta duração (o que a sociologia francesa denomina débrayage), paralisações espontâneas apareceram com maior nitidez na cena sindical, muito embora ainda não se tenha dado a devida atenção ao fenômeno. De fato, parece que as greves por fora são características deste novo ciclo grevista, porém ainda carentes de estudos. Motivo pelo qual ainda não se pode precisar com o devido rigor este termo por fora. Ou seja, se estas modalidades questionam a estrutura sindical como um todo (a forma-sindicato), se apenas se voltam contra as direções sindicais ou se não possuem nenhuma intencionalidade específica, figurando como meros acasos. 
Apesar de o sistema de dados do DIEESE não captar, com precisão, as greves por fora $^{10}$, há razões suficientes para crer que muitas manifestações vêm ocorrendo às margens do sindicato. Em primeiro lugar, muitas greves rebentaram espontaneamente e sem a presença da direção sindical, mas logo foram por esta assumidas na mesa de negociações, fazendo com que o sistema de dados do DIEESE, seguindo o padrão da OIT, não as considerassem por fora do sindicato. Em segundo lugar, os dados preliminares apontaram mais de 40 aparições de greves, desde 2010, cujo comando (origem da deflagração) continha a palavra "outros", ou seja, greves que não foram organizadas pelos sindicatos oficiais.

Como já se disse, o noticiário nacional se surpreendeu com a paradigmática greve dos garis cariocas em março de 2014 que, apesar de convocada pelo sindicato oficial, foi prolongada espontaneamente pelos trabalhadores, que não aceitaram o rebaixado acordo assinado pela sua entidade representativa. Ou mesmo diante da greve dos motoristas e trabalhadores rodoviários de São Paulo, naquele mesmo ano, donde os trabalhadores deflagraram uma greve independentemente de suas direções sindicais. Finalmente, para ficar apenas em exemplos paradigmáticos, as greves por fora dos trabalhadores das usinas Jirau e Santo Antônio (CAMPOS, 2016, p. 132-180) trouxeram o mesmo espanto dos órgãos da mídia - pelas mesmas razões mediante as quais costumam se opor a quaisquer modalidades paredistas - e das direções sindicais, estas receosas em perderem, na prática, a representação sindical.

Junto com o espanto veio a incompreensão. Ao invés de buscar a fundo as razões dos grevistas e as significações de seus atos isolados, independentes ou mesmo contrários à estrutura sindical, grande mídia e sindicatos oficiais mantiveram as mesmas posturas ao condenar, pura e simplesmente, tais experiências. Assim, independentemente do mérito destas greves, cimentou-se a via repressiva para que o Judiciário apreciasse os fatos ao seu modo, afastando-se as possibilidades compreensivas destas experiências no sentido da

\footnotetext{
${ }^{10}$ Isto por duas razões: a mídia sindical omite a origem da greve, temerosa em parecer "perder o controle", e a mídia tradicional não preocupa com estes detalhes. No mais, agradecemos a Rodrigo Linhares por nos franquear o acesso aos resultados das buscas de greves por fora no Sistema de Acompanhamento das Greves do DIEESE.
} 
crítica quanto às insuficiências da estrutura sindical diante das novas dinâmicas da classe trabalhadora.

\section{O PODER JUDICIÁRIO DIANTE DO NOVO CICLO DE GREVES}

Basicamente, a apreciação judicial deste novo ciclo grevista mantém os pilares estruturais dados pela Constituição de 1988 que, no limite, assumem a funcionalidade repressiva legada do Poder Executivo no período militar (BARISON, 2016); paradoxalmente, no processo de transição democrática, a interdição às greves foi aprimorada e o Poder Judiciário tornou-se "um verdadeiro bastião antissindical" (CORREGLIANO, 2014, p. 113).

Motivo pelo qual, diante destas novas formas grevistas que são deflagradas por categorias até então "passivas", a magistratura percebeu um aumento nos dissídios coletivos de greve e nas ações cautelares inibitórias do exercício da greve. Para além do aspecto quantitativo, em face das supracitadas experiências dadas à margem dos sindicatos, o Judiciário se viu diante de uma tensão no seio da forma jurídica: quem são os sujeitos de direito aptos a receberem a punição quando das greves por fora?

Na greve dos garis cariocas, o Tribunal Regional do Trabalho da 1a Região (TRT/RJ), após ver sua ordem judicial de retorno ao trabalho ser descumprida, intimou o sindicato oficial (representando fictamente toda a categoria), a prefeitura e a Comlurb (Companhia Municipal de Limpeza Urbana) à mesa de negociação até conseguir dar fim ao impasse. Em que pese o fato de o sindicato obreiro não concordar com a continuidade da greve, tendo inclusive firmado um acordo coletivo. Fórmula esta repetida pelo mesmo Tribunal no conflito dos rodoviários cariocas, ocasião em que a Desembargadora Maria das Graças Cabral Viegas Paranhos "resolveu" a tensão gerada no seio da forma jurídica.

Nós temos uma lei de greve e ela tem que ser respeitada. Eles [os rodoviários] têm que, dentro do sindicato, procurar resolver essas questões. Se eles discutem a legitimidade do sindicato, eles têm que ajuizar uma ação, fazer as provas que julgarem cabíveis e o juiz vai dizer se o sindicato é ou não legítimo representante. Mas enquanto nós temos uma diretoria constituída, nós não podemos admitir que uma comissão de dissidentes seja parte no processo (grifos não originais) ${ }^{11}$.

\footnotetext{
11 Disponível em http://g1.globo.com/rio-de-janeiro/noticia/2014/06/trt-decide-em-audiencia-que-greve-derodoviarios-do-rio-e-ilegal.html. Acesso em 7 de dezembro de 2016.
} 
Já na greve dos rodoviários de São Paulo, o TRT da 2a Região surpreendentemente aplicou uma multa de igual valor (cem mil reais) ao sindicato dos trabalhadores e ao sindicato patronal, por não haverem chegado a um termo. Não sem antes considerar que o sindicato é o único representante legítimo para compor a lide, face ao princípio da unicidade sindical $^{12}$.

Nestes casos, o judiciário decidiu porque é de sua natureza fazê-lo; e o direito não pode deixar os fatos sociais a esmo, sem seu devido enquadramento. Mas há de se convir que as respostas jurídicas foram improvisadas (ou até mesmo aleatórias), reveladoras de uma tensão no agir do judiciário, com vistas à mais apropriada proteção do núcleo central da estrutura jurídica - a abstração real do sujeito de direito.

A condenação do sindicato dos trabalhadores figurou como uma "palmatória", em razão deste não ter logrado controlar e moderar a força de trabalho que representa. É nestas decisões judiciais que se percebe, implícita ou explicitamente, a veia "pedagógica" do Poder Judiciário, ensinando aos trabalhadores e aos seus sindicatos qual deveria ser o seu lugar.

Voltou-se as costas à realidade para manter o seguro núcleo jurídico-formal: o sujeito de direito dentro do qual não cabe o imprevisível e o espontâneo das massas, que já não aceitam mais os conhecidos jogos de cena da campanha salarial, decretação de estado de greve, mediação na Seção de Dissídios Coletivos e, finalmente, aceitação do acordo proposto pelo empregador (não sem antes o diretor sindical dizer: "foi o melhor que arrancamos para a categoria").

De todo modo, as aparições de greves ou mobilizações ativadas sem a presença da entidade sindical não são raras, e uma acurada pesquisa jurisprudencial permitiu desvelar parcialmente esta realidade. A busca de sentenças e acórdãos nos sítios eletrônicos dos TRT-2 e TRT-15 evidenciou a recorrência "subterrânea" destas modalidades de luta sindical, no mais das vezes operadas individualmente ou por pequenos grupos de

\footnotetext{
${ }^{12} \mathrm{Na}$ audiência de conciliação ocorrida em 22 de maio de 2014, declarou a Desembargadora Rilma Hemetério que a "única representação legítima de trabalhadores é o sindicato, que no Brasil é único, por categoria. Portanto, só poderão se pronunciar os dois lados: empregadores e sindicato". Disponível em: http://www.redebrasilatual.com.br/cidadania/2014/05/motoristas-de-sp-desembargadora-diz-que-sindicato-e-unicorepresentante-legitimo-6188.html. Acesso em: 2 dez.2016.
} 
trabalhadores às margens dos seus sindicatos representativos; movimentos, em geral, de curta duração e que rebentam espontaneamente - as assim chamadas "greves-surpresa".

De plano, dada a impossibilidade de pesquisa em todos os Tribunais dos Estados da Federação, fez-se necessária a delimitação da busca de pronunciamentos judiciais provenientes da Justiça do Trabalho e, no meio desta, dos Tribunais Regionais da 2a e 15a Região, abarcando o estado de São Paulo. O recorte geográfico esboçado nesta amostragem levou em consideração a posição do estado de São Paulo na economia nacional, onde se situa o maior contingente de pessoas economicamente ativas e atuantes no mercado de trabalho ${ }^{13}$, além de serem os dois maiores Tribunais Regionais do Trabalho do país (BRASIL, 2015). E, apesar de serem observadas greves espontâneas de servidores públicos do regime estatutário, atraindo a competência para a Justiça Comum/Federal, a atual fase da pesquisa apenas permitiu a consulta aos julgados da Justiça do Trabalho, possivelmente por ali estarem os resultados mais relevantes.

Acredita-se que tal expediente empírico reforçou a hipótese de que as greves por fora da estrutura sindical são mais recorrentes do que pareciam, e o próprio modo individual de sua judicialização está a sugerir a impossibilidade de contenção de um vasto fenômeno conflitivo às paredes do sólido edifício sindical chancelado pelo Estado - o que aqui se denomina provisoriamente de transbordamento das greves. Isto é, as manifestações, paralisações e protestos de poucos grupos nos locais de trabalho irrompem com o completo desconhecimento ou omissão dos diretores das entidades sindicais oficiais; transbordam do sindicato, por assim dizer.

Quanto ao conteúdo das decisões judiciais, insta salientar que a análise não pretendeu criticar ou referendar as diversas motivações ideológicas subjacentes ou as conclusões da casuística. É bem verdade que a maioria das decisões do Judiciário Trabalhista paulista não acolheu a tese de que haveria falta grave abstratamente, tão somente pelo fato do trabalhador participar de movimento grevista reputado ilegal, a teor da Súmula no 316 do STF. Ou seja, pode-se adiantar a conclusão de que, no Estado de São

\footnotetext{
13 Cf. Pesquisa Mensal de Emprego de fevereiro de 2016, realizada pelo IBGE. Disponível em: http://www.ibge.gov.br/home/estatistica/indicadores/trabalhoerendimento/pme_nova/defaultmicro.shtm. Acesso em: 3 dez. 2016.
} 
Paulo, a Justiça Laboral se inclina para a indispensabilidade de se averiguar, no caso concreto, a prática individualizada de falta grave, seja com a depredação do patrimônio da empresa, seja com comprovadas ações violentas, ameaças, etc. Em que pese o fato de ainda serem encontradas decisões mais restritivas (confirmando a justa causa aplicada ao empregado que participa de greve formalmente reputada ilegal, mesmo ausente a prática individual de falta grave), a tendência geral parece ser oposta.

Primariamente, a investigação que se propôs foi de outra ordem: atestar a existência e persistência oculta das greves por fora dos sindicatos. O que não obstaria, de modo algum, direcionar lateralmente a crítica às tendências restritivas e formalistas que extraem das paralisações paralelas à estrutura sindical indícios aprioristicamente caracterizadores da falta grave do empregado e que, portanto, legitimariam a rescisão por justa causa.

Assim, no TRT-2 foram encontradas 22 sentenças e acórdãos, de janeiro de 2013 a novembro de 2016 envolvendo greves por fora. E, para o mesmo período, no TRT-15, foram encontradas 34 sentenças e acórdãos. Do estudo da totalidade destas decisões, verificou-se uma maioria de processos individuais ${ }^{14}$, donde se busca a reversão da justa causa aplicada ao empregado que se ativou em greves "selvagens", ou seja, espontaneamente deflagradas sem a presença do sindicato. O restante era composto de dissídios coletivos do trabalho envolvendo greves por fora ${ }^{15}$.

É bem verdade que estes resultados representam cerca de $5 \%$ por total de resultados cujas palavras-chave de busca foram "greve surpresa", "greve selvagem", "greve espontânea" e "greve e justa causa". Porém, o baixo percentual não deixa de revelar uma realidade subjacente de latência de conflitos deflagrados em face da empresa e do sindicato. Neste sentido, foram constantes as aparições de vigilantes terceirizados

\footnotetext{
${ }^{14}$ Destas, destacam-se: BRASIL. TRT-2. Proc. no 0000902-10.2014.5.02.0089. Ac. no 20160194096. Rel. Carlos Husek. 15a Turma. Publ. 19.abril.2016. BRASIL. TRT-2. Proc. no 0000557-34.2013.5.02.0039. Ac. no 20150809268. Rel. Des. Sergio Roberto Rodrigues. 11a Turma. Publ. 22.setembro.2015. BRASIL. TRT-15.Proc. no 0000748-23.2014.5.15.0091. Ac. no 039182/2015. Rel. Des. Ricardo Laraia. 6a Câmara. 3ㅡ Turma. DEJT. 17.07.15.

${ }^{15}$ Destes, destacam-se: BRASIL. TRT-2. Proc. no DCG-1001184-70.2015.5.02.0000. Rel. Des. Rafael Pugliese. SDC. Publ. 20.02.2016. BRASIL. TRT-15. Proc. no 0000833-59.2012.5.15.0000. Ac. no 000309/2012. Rel. Des. Antonio Francisco Montanagna. SDC. DEJT: 28.09.2012.
} 
que "cruzaram os braços" espontaneamente em razão de mora salarial ou descontos indevidos, ou mesmo garçons que promoveram "motins" contra os erros de cálculo das gorjetas.

Para além da confirmação fática desta realidade, a análise de jurisprudência na Justiça do Trabalho paulista revelou um relativo apreço ao direito individual e uma tensão não resolvida no âmbito coletivo. Assim, convivem paradoxalmente a relativa garantia ao exercício individual do direito de greve e a punição ilógica aos entes coletivos de representação dos trabalhadores. Máxime desta tensão observa-se na ementa publicada no bojo do dissídio de greve dos trabalhadores rodoviários de Jundiaí/SP, ávida pela localização do sujeito de direito que receba a punição:

GREVE. ATIVIDADE ESSENCIAL. PRECIPITAÇÃO DO MOVIMENTO PAREDISTA PROVOCADA POR OUTRAS PESSOAS ENQUANTO A DIREÇÃO DO RESPEITANTE SINDICATO ESTAVA DANDO REGULAR ANDAMENTO À NEGOCIAÇÃO COLETIVA. ABUSIVIDADE. RESPONSABILIDADE DO SINDICATO. QUANDO A CATEGORIA NÃO PODE SER RESPONSABILIZADA PELA PRECOCE EXPLOSÃO DA GREVE. ESTABILIDADE. OFÍCIO AO MINISTÉRIO PÚBLICO DO TRABALHO PARA APURAÇÃO DE RESPONSABILIDADE POR PRÁTICA DE ATOS ANTISSINDICAIS, COM AS POSSÍVEIS CONSEQUÊNCIAS ENTÃO DECORRENTES. Conquanto inquestionável ser a greve um direito fundamental, sendo amplo o seu exercício, nem por isso pode explodir ignorando as disposição legais, constitucionais e infraconstitucionais que disciplinam o seu exercício, pelas repercussões que provoca no meio social, máxime quando de atividade essencial se cuida. Inadmissível seja, de maneira abrupta e imprevista, interrompida a negociação coletiva, sem a observância das formalidades legais, não servindo para alforriar o sindicato de sua responsabilidade, atribuir a sua eclosão à atividade de pessoas estranhas a direção da entidade sindical, designadamente quando, ainda assim, esta assume, mesmo que em momento logo seguinte, a condução do movimento grevista. Embora possível o desencontro de posições, entre os trabalhadores, pretendendo a greve, e a direção do sindicato, não a desejando, por motivos vários, tanto uns, como da outra, para que seja lícita a atuação direta dos trabalhadores, antes, de procurar e saber se as entidades sindicais de grau superior não assumem/conduzem o movimento grevista. Situação que não pode redundar em prejuízo para os integrantes da categoria, de maneira que, não obstante reconhecida a abusividade da paralisação, de reconhecer o direito a estabilidade provisória, o que, contribuirá, com bastante intensidade, para por cobro, de maneira definitiva, ao movimento paredista, contribuindo, destarte, de forma mais incisiva para a pacificação social. De todo interesse a expedição de ofício ao Ministério Público do Trabalho, para apuração de responsabilidade por prática de atos antissindicais, com as possíveis consequências então decorrentes (grifos não originais).

De modo mais ou menos explícito, para além da punição pelas aduzidas violações aos requisitos formais da Lei de Greve, a mensagem do Judiciário Trabalhista foi clara ao 
punir o sindicato por não manter o controle de sua base. É justamente isto que o Estado espera de um sindicato que lhe é vinculado: autocontrole das convulsões obreiras.

Em resumo, a posição do Poder Judiciário diante das novas paralisações espontâneas e isoladas que irrompem neste novo ciclo ainda busca resguardar o direito individual ao melhoramento do contrato de trabalho, obtido pela greve, por força da Súmula no 316 do STF. É claro que exceções a esta regra protetiva sempre serão encontradas. Todavia, o que mais desafia a lógica é a relação no cenário do direito coletivo do trabalho. Como que esquecendo, ou mitigando, o princípio da liberdade sindical, o Judiciário afere responsabilidade à entidade sindical que não participou de uma greve espontânea, como se o sindicato fosse o "maior responsável" do movimento ocorrido em sua base. A inevitável torsão lógica atinge o âmago da forma jurídica calcada no sujeito de direito, persistindo a questão: como seria possível a responsabilização de um sujeito de direito alheio a determinado fato que possui relevância jurídica?

\section{CONCLUSÃO}

O conceito empírico de ciclo de greves, apesar de não ser o único instrumental compreensivo disponível ao pesquisador, possui o mérito de fornecer um retrato aproximado da dinâmica sindical em determinado momento. Ao se referenciar a análise nesta chave conceitual, buscou-se captar algumas características do movimento sindical recente. Defendeu-se, neste estudo, a tese mediante a qual se iniciara no Brasil um novo ciclo grevista a partir de 2004. Ainda é cedo para aferir, com absoluta certeza, se este ciclo manterá um padrão de expansão, de estagnação ou de retração. A conjuntura econômica recessiva, o processo do impeachment, a política de austeridade fiscal impulsionada pelo Governo Temer e os resultados das negociações coletivas de $2016^{16}$ induzem uma conjectura de retração ou mesmo crise deste ciclo. O tempo dirá.

Neste diapasão, um movimento "subterrâneo" ocorrido no ápice deste novo ciclo foram as greves por fora dos sindicatos. Apesar da incipiência desta caracterização,

\footnotetext{
${ }^{16}$ O DIEESE sistematizou o balanço dos reajustes somente até o primeiro semestre de 2016, demonstrando o crescimento dos reajustes inferiores ao INPC. Se em 2013, 87\% dos reajustes ficaram acima deste índice, em 2015 tal percentual cai para 76,5\% e chega ao primeiro semestre de 2016 com apenas 26,9\% das negociações acima do INPC. (CORREGLIANO, 2016; DIEESE, 2016).
} 
acredita-se que tal noção poderia jogar luz sobre um fenômeno recente e pouco estudado. Será que estas greves figuram como a, até então, inexprimível confissão de que algo vai mal no regime da unicidade sindical? Mesmo episódicas e isoladas, estas modalidades grevistas estariam a significar algo além de sua processualidade concreta, no sentido da revitalização ou reforma da estrutura sindical? O tempo dirá.

Finalmente, o Poder Judiciário. Vocacionado a repelir o arbítrio, o Judiciário absorveu uma tensão inconciliável no seio da forma jurídica, atinente à escolha do sujeito de direito destinatário do comando judicial sancionatório. Não seria o caso de a crítica jurídica franquear caminhos lógicos para a solução no caso concreto, eis que estas tensões formais do direito não podem ser resolvidas uma dose de artificialidade. Uma coisa é certa: o essencial do fenômeno restou incompreendido, e o Judiciário nada mais fez senão aprofundar a sofisticação do controle repressivo das greves, porém, desta vez, oferecendo soluções aleatórias, ilógicas e improvisadas. Até quando os sindicatos e trabalhadores permanecerão obedientes aos comandos judiciais violadores da liberdade sindical, é impossível dizer. O tempo dirá.

\section{REFERÊNCIAS}

AMORIM, Wilson Aparecido Costa de. As greves de 2011 e 2012. Informações FIPE, São Paulo, São Paulo, n. 377, p. 22-32, fev/2012. Disponível em: http://downloads.fipe.org.br/content/downloads/publicacoes/bif/2012/2_BIF377a.pdf. Acesso em: 12 jan. 2017.

ANTUNES, Ricardo; SILVA, Jair Batista da. Para onde foram os sindicatos? Do sindicalismo de confronto ao sindicalismo negocial. Caderno CRH, Salvador, v. 28, n. 75, p. 511-528, set./dez. 2015. Disponível em: http://dx.doi.org/ 10.1590/S0103-49792015000300005. Acesso em: 12 jan. 2017.

BABOIN, José Carlos de Carvalho. 0 tratamento jurisprudencial da greve política no Brasil. 177p. Dissertação (Mestrado em Direito do Trabalho) - Faculdade de Direito, Universidade de São Paulo, 2013.

BARISON, Thiago. A estrutura sindical de Estado no Brasil e o controle judiciário após a Constituição de 1988. São Paulo: LTr, 2016. 
BOITO JR., Armando. A nova burguesia nacional no poder. In: Armando Boito Jr.; Andréia Galvão (orgs.). Política e classes sociais no Brasil dos anos 2000. São Paulo: Alameda Editorial, 2012a. p. 69-106.

BOITO JR., Armando; GALVÃO, Andréia; MARCELINO, Paula. La nouvelle phase du syndicalisme brésilien (2003-2013). Cahiers des Amériques Latines, n. 80, p. 145-164, jul. 2015. Disponível em: https://cal.revues.org/4184. Acesso em: 12 jan. 2017.

BOITO JR., Armando; MARCELINO, Paula. O sindicalismo deixou a crise para trás? um novo ciclo de greves na década de 2000. Caderno CRH, Salvador, v. 23, n. 59, p. 323-338, maio/ago. 2010.

BRASIL. Conselho Nacional de Justiça. Justiça em Números 2015: ano-base 2014. Brasília: CNJ, 2015, p. 174. Disponível em: http://www.cnj.jus.br/programas-e-acoes/pj-justicaemnumeros. Acesso em: 12 jan. 2017.

CAMPOS, Cauê Vieira. Conflitos trabalhistas nas obras do PAC: o caso das Usinas Hidrelétricas de Jirau, Santo Antônio e Belo Monte. 201p. Dissertação (Mestrado em Ciência Política) - Instituto de Filosofia e Ciências Humanas, Universidade Estadual de Campinas. Campinas, 2016.

CARDOSO, Adalberto Moreira. Dimensões da crise do sindicalismo brasileiro. Caderno CRH, Salvador, v. 28. n. 75, p. 493-510, set./dez. 2015.

CORREGLIANO, Danilo Uler. Por quê agora? (sobre a suspensão da Súmula no 277 do TST). Disponível em: https://grupodepesquisatrabalhoecapital.wordpress.com/2016/11/06/porque-agora-sobre-a-suspensao-da-sumula-no-277-do-tst-por-danilo-uler-corregliano/.

Acesso em: 12 jan. 2017.

CORREGLIANO, Danilo Uler. O sistema de controle judicial do movimento grevista no Brasil: da greve dos petroleiros de 1995 aos dias atuais. 176p. Dissertação (Mestrado em Direitos Humanos) - Faculdade de Direito, Universidade de São Paulo. São Paulo, 2014.

DIEESE. Balanço das negociações dos reajustes salariais do 10 semestre de 2016. Estudos e pesquisas, São Paulo, Dieese, n. 81, set. 2016. Disponível em: http://www.dieese.org.br/balancodosreajustes/2016/estPesq81balanco

Reajustes1semestre2016.pdf. Acesso em: 12 jan. 2017.

DIEESE. Balanço das greves em 2013. Estudos e pesquisas, São Paulo, Dieese, n. 79, dez. 2015.

http://www.dieese.org.br/balancodasgreves/2013/estPesq79balancogreves2013.pdf. Acesso em: 12 jan. 2017.

FESPSP. O jovem e a política na cidade de São Paulo. São Paulo: FESPSP, 2014. Disponível em: http://www.fespsp.org.br/fesp/uploads/fck_assets/arquivos/infografico.pdf. Acesso em: 12 jan. 2017.

GALVÃO, Andréia. A contribuição do debate sobre a revitalização sindical para a análise do sindicalismo brasileiro. Crítica Marxista, Campinas/São Paulo, n. 38, p. 103-117, 2014. Disponível

em: 
http://www.ifch.unicamp.br/criticamarxista/sumario.php?id_revista=49\&numero_revista= 38. Acesso em: 12 jan. 2017.

GALVÃO, Andréia. A reconfiguração do movimento sindical no governo Lula. Outubro, $\mathrm{n}$. 18, 1.sem.2009. Disponível em: http://outubrorevista.com.br/wpcontent/uploads/2015/02/Revista-Outubro-Edic\%CC\%A7a\%CC\%83o-18-Artigo-07.pdf. Acesso em: 12 jan. 2017.

GARCIA, Raphael Tsavkko. Greve de garis no Rio de Janeiro: da luta à vitória. Sítio eletrônico Global Voices. Disponível em: http://pt.globalvoicesonline.org/2014/03/11/greve-de-garis-no-rio-de-janeiro-da-luta-avitoria/. Acesso em: 12 jan. 2017.

IBGE - Instituto Brasileiro de Geografia e Estatística. Indicadores IBGE: principais destaques da evolução do mercado de trabalho nas regiões metropolitanas abrangidas pela pesquisa. Rio de Janeiro: IBGE, 2012a. Disponível em: http://www.ibge.gov.br/home/estatistica/indicadores/trabalhoerendimento/pme_nova/r etrospectiva2003_2011.pdf. Acesso em: 12 jan. 2017.

IBGE - Instituto Brasileiro de Geografia e Estatística. Pesquisa mensal de emprego: evolução do emprego com carteira de trabalho assinada 2003-2012. Rio de Janeiro: IBGE, 2012b.

Disponível

em: http://www.ibge.gov.br/home/estatistica/indicadores/trabalhoerendimento/pme_nova/E volucao_emprego_carteira_trabalho_assinada.pdf. Acesso em: 12 jan. 2017.

IBOPE. Índice de confiança social 2015. Brasil: Ibope inteligência, 2015. Disponível em: http://www.ibope.com.br/pt-br/noticias/Documents/ics_brasil.pdf. Acesso em: 12 jan. 2017.

KREIN, José Dari; DIAS, Hugo Rodrigues; COLOMBI, Ana Paula Fregnani. As centrais sindicais e a dinâmica do emprego. Estudos Avançados, São Paulo, v. 29. n. 85, p. 121-135, set./dez. 2015. Disponível em: http://www.scielo.br/pdf/ea/v29n85/0103-4014-ea-29-8500121.pdf. Acesso em: 12 jan. 2017.

LINHARES, Rodrigo. As greves de 2011 a 2013. Revista de Ciências do Trabalho, São Paulo, DIEESE, n. 5, p. 97-112, dez. 2015. Disponível em: http://rct.dieese.org.br/rct/index.php/rct/article/view/97/pdf. Acesso em: 12 jan. 2017.

NORONHA, Eduardo Garuti. Ciclo de greves, transição política e estabilização: Brasil, 19782007. Lua Nova, São Paulo, n. 76., p. 119-236, 2009. Disponível em: http://www.scielo.br/pdf/ln/n76/n76a05.pdf. Acesso em: 12 jan. 2017.

NORONHA, Eduardo Garuti. Greves na transição brasileira. 352p. Dissertação (Mestrado em Ciências Sociais). Instituto de Filosofia e Ciências Humanas, Universidade Estadual de Campinas, 1992.

PIZZORNO, Alessandro. Los sindicatos y la acción política. Economía y Política en acción sindical. Cuadernos del passado y presente. Córdoba: Pasado y Presente, 1974. 
PONCE, Pedro Augusto. Ciclos de greves: o peso da variável salarial na literatura nacional e internacional das greves. 73p. Dissertação (Mestrado em Ciência Política). Universidade Federal de São Carlos, 2013.

RODRIGUES, Iram Jácome. Trabalhadores e sindicalismo no Brasil: para onde foram os sindicatos?. Caderno CRH, Salvador, v. 28, n. 75, p. 479-491, set-dez/2015.

SINGER, André. Cutucando onças com varas curtas: o ensaio desenvolvimentista no primeiro mandato de Dilma Roussef (2011-2014). Novos estudos, São Paulo, n. 102, p. 4371, Jul. 2015.

TILLY, Charles. From mobilization to revolution. Ann Arbor/Michigan: Addison-Wesley, 1978.

TRÓPIA, Patrícia Vieira; GALVÃO, Andréia. MARCELINO, Paula. A reconfiguração do sindicalismo brasileiro nos anos 2000: as bases sociais e o perfil político-ideológico da Conlutas. Opinião Pública, Campinas, v. 19, n. 1, p. 81-117, jun. 2013. 